Cadernos de História, Belo Horizonte, v. 22, n. 37, Novembro de 2021

DOI: https://doi.org/10.5752/P.2237-8871.2021v22n37p127-143

\section{AJUSTANDO ESTRATÉGIAS: A EXPERIÊNCIA COM O BASquetebol no SPORT Club Mackenzie (Rio de JANEIRO,} 1924-1941)
ViCTOR MELO

Universidade Federal do Rio de Janeiro victor.a.melo@uol.com.br

Bruno Adriano Rodrigues Silva

Universidade Federal do Estado do Rio de Janeiro b.adriano_rs@yahoo.com.br

\title{
Resumo
}

Em 1914, foi criada uma associação marcante na história do Méier, bairro/distrito do Rio de Janeiro: o Sport Club Mackenzie, a princípio eminentemente dedicado ao futebol. Com o passar dos anos, nessa agremiação, outros esportes passaram a ser mais praticados, sendo um deles, o basquetebol. Este artigo tem por objetivo discutir tal experiência com a modalidade da bola ao cesto, percebendo-a como decorrência de decisões administrativas adotadas, tendo em vista a manutenção de vínculos com a elite carioca, organizada em ligas esportivas prestigiosas - uma estratégia entabulada para reafirmar compromissos de contribuição com a valorização local. Para alcance do objetivo, como fontes, foram utilizados periódicos publicados na cidade. Mais do que uma reflexão sobre a ampliação da cultura esportiva da capital nacional - naquela ocasião -, trata-se de lançar um olhar para os relacionamentos estabelecidos entre as suas zonas urbana e suburbana. Portanto, intenta-se explicitar posicionamentos assumidos por certos grupos sociais para buscar inserção em um cenário citadino progressivamente complexo e em constante transformação.

Palavras-chave: História do Esporte; basquete; subúrbio.

Recebido em 8 de janeiro de 2021.

Aprovado em 8 de março de 2021. 
Cadernos de História, Belo Horizonte, v. 22, n. 37, Novembro de 2021

DOI: https://doi.org/10.5752/P.2237-8871.2021v22n37p127-143

\section{Adjusting STRATEGIES: BASKETBALL EXPERIENCES IN Sport Club Mackenzie (Rio DE JANEIRO, 1924-1941)}

ViCTOR MELO

Universidade Federal do Rio de Janeiro victor.a.melo@uol.com.br

Bruno Adriano Rodrigues Silva

Universidade Federal do Estado do Rio de Janeiro

b.adriano_rs@yahoo.com.br

\begin{abstract}
In 1914, a remarkable association was founded in the history of Méier, a Rio de Janeiro neighborhood: the Sport Club Mackenzie, at first, evidently dedicated to football. Over the years, other sports began to be more practiced in this association, including basketball. This article aims to discuss this experience with the ball-in-the-basket modality, as a way to highlight some administrative decisions adopted in order to maintain relationship to the city's elite organized in prestigious leagues - a strategy to reaffirm agreements in order to contribute with the enhancement of the neighborhood. Periodicals published in the city were used as sources to achieve our goal. More than a reflection on the expansion of the sporting culture of the national capital - at that time -, it aims to focus on the relationships between the urban and suburban areas. Then, we intend to explain the stands which have been taken on some points by certain social groups to seek insertion in a city scenario in constant transformation.
\end{abstract}

Keywords: Sport History; basketball; suburb. 


\section{INTRODUÇÃo}

De acordo com o recenseamento do Rio de Janeiro, realizado no ano de 1906, o distrito do Méier $^{1}$, parte da zona urbana da cidade, fronteiriça com a suburbana ${ }^{2}$, possuía 34.476 habitantes. Naquele momento, os distritos urbanos possuíam um contingente populacional (621.933) maior do que os suburbanos (183.402) (BRASIL, 1907).

No decorrer do século XX, contudo, foi se invertendo tal concentração populacional. Uma das desencadeadoras dessa mudança foi a série de reformas urbanas promovidas nas décadas iniciais da centúria, com destaque para as intervenções realizadas na gestão de Francisco Pereira Passos, designado como prefeito plenipotenciário pelo presidente da República, Francisco de Paula Rodrigues Alves (1902-1906) (SEVCENKO, 1983).

Em diferentes distritos, principalmente nos da região central, morros foram desbastados, aterros promovidos, ruas e avenidas abertas, construídas novas edificações de inspiração europeia, a mobilidade ampliada por meio da instalação de linhas de bonde e trem (SILVA, 2019).

Intensificou-se também a regulação do uso do espaço urbano. As preocupações com as condições de saúde e higiene - claramente manifestas nas intervenções na distribuição de água e saneamento público, bem como nas ações de combate às epidemias, de um lado, incidiram no estímulo à prática de exercícios físicos, como o esporte a ginástica, de outro, serviram como argumento para a remoção violenta da habitação dos mais pobres de algumas áreas da cidade (MELO, 2009; SILVA, 2009).

Isso é, as reformas ocasionaram intensas transformações na paisagem, na arquitetura, na infraestrutura urbana, nos comportamentos dos indivíduos, enfatizando-se a disseminação de práticas consideradas civilizadas - um claro processo de adesão a parâmetros de modernidade (ABREU, 1987). Nesse cenário, desencadeou-se um processo de gentrificação das zonas central e sul.

Impedidos de seguir vivendo nas regiões consideradas nobres do Rio de Janeiro, boa parte da população mais pobre foi morar nos subúrbios, assim como gente de estrato médio, que não podia manter o padrão de vida das zonas Centro e Sul. O aperfeiçoamento dos serviços de transporte público facilitou essa maior ocupação do interior da cidade (FERNANDES, 2009).

Claramente se percebe tal processo no recenseamento de 1920. O Méier passou a contar com 57.252 habitantes (BRASIL, 1923). É relevante ressaltar que, no distrito em questão, localizado relativamente próximo da área central da cidade, passaram a morar muitos funcionários públicos civis e militares, comerciários, bem como profissionais liberais, notadamente médicos, engenheiros e advogados (MENDONÇA, 2011).

Dado seu perfil societário e em função de sua localização limítrofe, não surpreende que o Méier tenha sido representado como capital dos subúrbios (REVISTA SUBURBANA, 1918), mesmo que oficialmente integrasse a zona urbana da cidade. No distrito, algumas lideranças entabularam ações diversas no sentido de desenvolver o local, reivindicar melhorias nas

1 Até 1903, o Rio de Janeiro era dividido em freguesias, posteriormente em distritos. Oficialmente, somente em 1981, estabeleceram-se os limites oficiais dos bairros, uma noção que, todavia, já existia desde o século XIX, utilizada usualmente pelos moradores.

2 No recenseamento de 1890, a cidade foi dividida em zona urbana e suburbana (MIYASAKA, 2016). 
condições de urbanidade, assim como combater estigmas que consideravam o subúrbio como uma região marcada pela desordem, incivilidade e violência (FERNANDES, 2009).

Entre outros aspectos, ajudou a reforçar a ideia de que o distrito se tratava de um lugar civilizado, a estruturação de iniciativas de sociabilidade pública dos mais distintos perfis, inclusive as de natureza associativa, tais como o Clube dos Fenianos e o Destemidos, dedicados às festas carnavalescas, bem como o Grupo Musical do Méier, promotor de concertos em espaços públicos (VIDA, 1909).

Entre as mais ativas e notáveis associações se encontravam as que tinham como motivação central as práticas esportivas, tais como o Clube Olímpico Riachuelense (GAZETA,1885) e o Clube Atlético Boca do Mato (GAZETA,1884), fundados ainda no século XIX, bem como o Riachuelo Futebol Clube (RIACHUELO, 1905), criado em 1905.

Naquele contexto de aumento populacional, diversificação societária e estruturação de iniciativas encaradas como sinal de modernização, foi criada, em 1914, uma associação marcante na história do Méier, ativa até os dias de hoje: o Sport Club Mackenzie. A princípio, eminentemente dedicado ao futebol, foi fundado por um grupo de jovens da elite local $^{3}$, interessados em participar das ações da modalidade que se espraiava pela cidade e se organizava por meio de ligas que promoviam campeonatos cada vez mais celebrados (MELO; SILVA, 2021).

Para além do aspecto esportivo, o Mackenzie foi um clube que adotou e se empenhou em difundir parâmetros de civilização e progresso por meio da organização de bailes, festas, cerimônias cívicas, atividades de escotismo, entre outras. Essas iniciativas também eram orientadas no sentido de combater os estigmas e de valorizar o Méier no cenário citadino (MELO; SILVA, 2021).

Se o futebol preponderou nos momentos iniciais do Mackenzie, com o passar dos anos, outras modalidades passaram a ser mais praticadas, entre as quais o basquetebol, uma mudança que foi mesmo registrada nos seus estatutos ${ }^{4}$ e consagrou seu caráter multiesportivo.

No momento em que a agremiação do Méier começou a se envolver com a modalidade da bola ao cesto, na década de 1920, esse esporte já possuía um sensível nível de estruturação no RJ. As iniciativas ao seu redor eram promovidas por uma liga que congregava importantes clubes e organizava um campeonato regular (CANCELA, 2010; FERREIRA JUNIOR, 2008).

Nesse cenário, como se estruturou a prática do basquete no Mackenzie? Como o envolvimento com a modalidade ajuda-nos a entender alguns projetos das diretorias? Isso nos auxilia a pensar na dinâmica citadina, especificamente no que tange ao relacionamento, por meio do esporte, entre as elites de diferentes regiões do Rio de Janeiro?

Tendo em vista essas questões, este artigo tem por objetivo discutir a experiência com o basquetebol no Sport Club Mackenzie, percebendo-a como decorrência de decisões administrativas adotadas, tendo em vista a manutenção de vínculos com a elite carioca organizada em ligas esportivas prestigiosas, uma estratégia mobilizada para reafirmar compromissos de contribuição com a valorização do bairro/distrito. No debate, consideramos o conceito de "associação", uma relação social permeada por regulamentos que são definidos e

\footnotetext{
3 Neste artigo, nos aproximamos do delineamento sociológico de Pareto (2010), para quem uma classe eleita ("élite") se constitui a partir dos índices mais elevados no ramo das atividades profissionais que desempenham os indivíduos e os grupos sociais em uma determinada sociedade.

4 Cf. Diário (1925) e Diário (1935).
} 
fiscalizados por indivíduos partícipes de uma razão administrativa com finalidades específicas (WEBER, 1987, p. 93).

Adotamos como recorte temporal o período compreendido entre os anos de 1924 e 1941, momento em que se estruturou o envolvimento pioneiro do Mackenzie com o basquetebol. Para alcance do objetivo, como fontes foram utilizados jornais e revistas publicados no Rio de Janeiro, no período em tela, tratados a partir de sua materialidade (LUCA, 2005), considerando-se as posições veiculadas como representações (CHARTIER, 1991) que nos permitem prospectar a intencionalidade das ações das diretorias do clube do Méier.

\section{Sport Club Mackenzie: o basquete como estratégia}

$\mathrm{Na}$ cidade do Rio de Janeiro, as primeiras iniciativas mais sistemáticas envolvendo o basquete foram promovidas, nos anos iniciais da década de 1910, pela Associação Cristã de Moços (GAZETA DE NOTÍCIAS, 1911); por agremiações como o América Futebol Clube (JORNAL DO BRASIL, 1914), o São Cristóvão Atlético Clube e o Sporting Club Rio de Janeiro (JORNAL DO BRASIL, 1915a); bem como por instituições escolares como o Colégio Sylvio Leite (O IMPARCIAL, 1916). Inicialmente, o “jogo da moda” (O PAIZ, 1914, p. 16) era organizado como parte de festivais esportivos (GAZETA DE NOTÍCIAS, 1915).

Em 1915, houve uma primeira tentativa de maior estruturação da modalidade, um campeonato promovido pela Liga Metropolitana de Esportes Atléticos, a mais prestigiosa da cidade, na qual se encontravam filiados os clubes mais imponentes, boa parte deles com sedes localizadas nas zonas Centro e Sul (JORNAL DO BRASIL, 1915b).

O modus operandi dessa liga procurava reafirmar a predominância econômica dessas zonas, inclusive no que dizia respeito ao poder de decisão política sobre os rumos do esporte no Rio de Janeiro (SANTOS, 2010). Essa dinâmica tinha como fundamento uma "racionalidade urbana” cujo intuito era espraiar as formas de dominação (LEFEBVRE, 2008, p. 81).

No ano seguinte, 1916, o basquete foi oficialmente incorporado à Liga, sendo, contudo, considerado secundário em relação ao futebol (JORNAL DO BRASIL, 1926). O velho esporte bretão galgava maior popularidade e prestígio na cidade (PEREIRA, 2000). Assim sendo, não surpreende que, somente em 1919, a entidade tenha promovido um campeonato mais bem estruturado (JORNAL DO BRASIL, 1919) e passado a tentar exercer um monopólio sobre a modalidade, não reconhecendo, inclusive, as iniciativas da pioneira Associação Cristã de Moços (JORNAL DO COMMERCIO, 1918, p. 6).

Para organizar as atividades de basquete, a Liga Metropolitana instituiu um conselho específico (O IMPARCIAL, 1919) que contava com a participação de clubes como Botafogo, Fluminense, Flamengo, Boqueirão, América, São Cristóvão e a Associação Cristã de Moços (JORNAL DO COMMERCIO, 1921). Transparecia o entusiasmo com a modalidade que se tornava rapidamente apreciada na cidade e era apresentada como dotada de "qualidades excepcionais" por educar todos os "músculos do corpo" e conferir "muita inteligência", sendo "aconselhável até mesmo às crianças e senhoritas", desde que "dentro das regras" (O

5 Desde o século XIX, o esporte paulatinamente se tornou um importante fórum de participação social feminina. No decorrer da centúria seguinte, o envolvimento de mulheres como torcedoras e jogadoras foi se tornando mais notável. O próprio Mackenzie, já nos seus primeiros anos de existência, foi um exemplo dessa ocorrência (MELO; SILVA, 2021). 
IMPARCIAL, 1919, p. 19).

Progressivamente, um maior número de clubes aderiu ao esporte da bola ao cesto. $\mathrm{O}$ torneio início de 1923, por exemplo, já contou com a participação de outras agremiações: Sport Club Brasil, Tijuca Tênis, Ginástico Português, Andaraí e Vasco da Gama (JORNAL DO BRASIL, 1923). Em 1924, todavia, uma ocorrência interferiu no seu desenvolvimento - uma cisão na Liga Metropolitana. As sociedades esportivas de maior expressão fundaram uma nova entidade: a Associação Metropolitana de Esportes Atléticos (AMEA).

A dissensão ocorreu fundamentalmente por razões de natureza política e econômica (SANTOS, 2010). As agremiações da elite carioca buscavam estabelecer mecanismos de status e distinção, vislumbrando exercer maior poderio para mais diretamente dirigirem os rumos esportivos da cidade (SOARES, 1999).

Na ocasião, o Mackenzie já era filiado à Liga Metropolitana havia alguns anos (FUTEBOL, 1916). Migrou para a AMEA, embora sem um consenso interno (A PALPITANTE, 1924). Nessa nova entidade, a agremiação do Méier teve suas primeiras experiências melhor estruturadas com o basquete. Antes, ocorreram apenas algumas poucas iniciativas de caráter interno (JORNAL DO BRASIL, 1924).

Para o Mackenzie, desde sua fundação, fazer parte de ligas prestigiosas era encarado como ser aceito em um âmbito valorizado da cidade, uma estratégia que as diretorias vislumbravam para ampliar a respeitabilidade pública do clube, justamente por aderir voluntariamente a uma autoridade esportiva reconhecida. Tratava-se de ser uma associação de tipo "heterônoma" (WEBER, 1987, p. 96).

Tal atitude era também considerada como uma forma de exaltação das virtudes locais. Essa foi a representação expressa no discurso de comemoração dos 10 anos do clube, quando se afirmou que: “(...) tendo à frente dirigentes esforçados e cheios de vontade, conseguiu o Mackenzie impor-se a 'grandes e pequenos' sempre em posições de destaque" (O IMPARCIAL, 1924, p. 11). Esse lugar intermediário, similar ao do fronteiriço Méier, foi constantemente buscado pela agremiação do Méier.

O problema é que fazer parte das ligas mais respeitadas significava dar conta de novas exigências, especialmente de caráter econômico e administrativo, algo bem notável no caso do futebol. A AMEA deixava isso claro a todo momento:

Nosso projeto, nesse ponto, era mais liberal que o anterior (...) pretendemos pugnar pela cultura do corpo, do espirito e da alma em todas as camadas sociais, mas exigiremos organização. Fomentaremos o preparo necessários a clubes novos, mas que nos garantam em seus programas e nas suas possibilidades administrativas normas de engrandecimento moral ${ }^{6}$

O presidente do Mackenzie, na ocasião, era José Soares Barbosa Junior, funcionário importante da Estrada de Ferro Central do Brasil (CORREIO DA MANHÃ, 1921). Por anos, ele empregou esforços para defender os interesses do clube junto à AMEA, em especial no que dizia respeito à necessidade de dispor de uma sede esportiva que atendesse às exigências da entidade (O IMPARCIAL, 1924). Para dar conta de tal obrigação, a agremiação do Méier adotou as mais diferentes estratégias, entre as quais, alugar espaços de outras associações, soluções, na verdade, sempre provisórias e paliativas (GAZETA DE NOTÍCIAS, 1925).

6 Ibid. 
Em relação à prática do basquete, o Mackenzie também enfrentou dificuldades administrativas. Em 1925, por exemplo, foi punido por ter faltado a uma partida do torneio início (JORNAL DO BASIL, 1925). Logo em seguida, comunicou à AMEA que, “(...) por motivo de força maior (...)", não poderia participar do campeonato anual (JORNAL DO BRASIL, 1925, p. 20). Nesse cenário, a modalidade perdeu espaço no clube que seguia tentando atender as necessidades do futebol e, em segundo plano, do atletismo (IMPARCIAL, 1926).

Isso ajuda a entender a falta de maiores referências nos jornais à prática do esporte da bola ao cesto no clube do Méier. Tardava a melhor se estruturar a modalidade na agremiação. Em 1928, por exemplo, o Mackenzie não disputou o “(...) encontro de basquetebol marcado com o Bangu A. C., fazendo assim a entrega dos pontos (...)”, partida prevista pelo torneio complementar da AMEA (JORNAL DO COMMERCIO, 1928, p. 7).

No ano seguinte, o Mackenzie participou mais ativamente das contendas, mas ainda incorreu em falhas, como deixar de enviar um delegado para um jogo do campeonato anual, o que resultou em uma multa imposta pela AMEA (O JORNAL, 1929, p. 10). De outro lado, melhor se estruturou seu departamento de basquete, que passou mais amiúde a convocar os jogadores para as partidas (DIÁRIO DA NOITE, 1930). Da mesma forma, árbitros vinculados à associação do Méier tornaram-se mais atuantes e reconhecidos (CORREIO DA MANHÃ, 1930). Paulatinamente, o clube administrava seus dilemas internos e percebia que o envolvimento com a modalidade poderia ser uma estratégia útil para seus intuitos.

Há que se ter em conta que o basquete era um esporte significativamente mais barato e fácil de operacionalizar do que o futebol, por envolver menor número de jogadores, por exigir instalações sensivelmente menores e menos custosas, por não estar, àquele momento, flertando com o profissionalismo como já ocorria com o ludopédio (SANTOS, 2008).

A variação do preço dos ingressos para as partidas, no decorrer dos anos 1920, é uma evidência das diferenças entre as modalidades. No início da década, em média, custava $2 \$ 000$ o bilhete mais barato para os encontros de basquete e futebol ${ }^{7}$. Ao final do decênio, a mesma entrada para um jogo do ludopédio passou a custar 6\$000 (JORNAL DO BRASIL, 1929, p. 14 ), enquanto para um da modalidade da bola ao cesto manteve-se em $2 \$ 000$ (CORREIO DA MANHÃ, 1929).

$\mathrm{Na}$ década de 1930, o maior investimento do Mackenzie no basquete ficou claro nas ações da diretoria presidida pelo “(...) conhecido e conceituado clínico, Dr. Dante Guarinello, mackenzista de fibra, que de certo, não poupará esforços pelo progresso do clube que tanta simpatia desfruta em nossa capital" (SPORT..., 1931, p. 13). Um exemplo foi sua participação na diretoria da AMEA propondo mudanças no regulamento, a fim de atenuar as dificuldades da agremiação que dirigia (FOOTBALL..., 1931).

Percebe-se que, a essa altura, diferentemente de outros momentos, o clube do Méier apresentava “(...) uma situação financeira bastante lisonjeira (...)” (O ANIVERSÁRIO..., 1931, p. 10), possuindo cerca de "400 sócios" que pagavam uma mensalidade de "(...) cinco mil réis, sendo que os diretores concorrem com uma mensalidade extra de trinta mil réis (...)". Contava com uma "praça de esportes modestamente aparelhada (...)", planejando, em breve, finalmente construir "suas quadras de tênis e basquetebol".

A participação contínua e sistemática do clube do Méier tinha também como finalidade

7 Cf. Santos, 2010; Jornal do Brasil, 1920) 
concretizar sua vinculação com a prestigiosa AMEA. Tornou-se regular a prática do basquete no Mackenzie em um cenário em que não parava de crescer a popularidade da modalidade no Rio de Janeiro (JORNAL DOS SPORTS, 1931). Os resultados começaram a surgir. Em 1931, foi o vice-campeão da segunda divisão do campeonato anual, atrás apenas do Olaria (JORNAL DOS SPORTS, 1931).

No ano seguinte, novo impulso teve o esporte na associação do Méier em função dos esforços de Eduardo Grota, integrante da Associação Cristã de Moços (DIÁRIO CARIOCA, 1932), como vimos, uma das instituições responsáveis pelo desenvolvimento da modalidade no Rio de Janeiro. Além de organizar um torneio interno, o Mackenzie uma vez mais participou integralmente do campeonato promovido pela AMEA (A NOITE, 1932).

Nesse mesmo ano de 1932, o Mackenzie comunicou à AMEA que, por dificuldades de cumprir o exigente regulamento, não mais participaria dos seus campeonatos de futebol (CORREIO DA MANHÃ, 1932), mantendo-se, contudo, nas contendas da bola ao cesto. Dirigido pelo funcionário público Newton Carvalho de Souza (CORREIO DA MANHÃ, 1930), o departamento de basquete ganhou visibilidade e relevância interna. A confecção de um novo uniforme para os certames - "antigamente todo branco (...) agora bonito e vistoso. Calção preto com escudo na camisa" (A NAÇÃO, 1933, p. 22) - é um indício de que a modalidade começou a receber mais recursos para se estruturar.

A essa altura, em 1933, foi criada uma entidade representativa exclusivamente dedicada à modalidade: a Liga Carioca de Basquete, perspectivada como uma alternativa às “(...) leis de arrocho da AMEA - a entidade que só acenou com um departamento autônomo quando viu fugirem as possibilidades de manterem o basquetebol acorrentado ao seu jugo politiqueiro" (JORNAL DOS SPORTS, 1933, p. 1). Passaram a integrar a iniciativa importantes clubes como o Fluminense, Vasco, América, Tijuca, Vila Isabel e Bonsucesso (JORNAL DOS SPORTS, 1933).

A agremiação do Méier logo filiou-se à Liga Carioca de Basquete (A NAÇÃO, 1933), participando de um "torneio de classificação" no qual apresentou inesperado desempenho: "Os últimos jogos provaram que todos os times merecem respeito. (...) o Vasco, em seu campo passou mal com o Mackenzie, tido até então como o armazém da pancada (...)" (JORNAL DOS SPORTS, 1933, p. 8).

Essa foi uma motivação definitiva para que o clube se envolvesse cada vez mais com a modalidade. Com isso, uma das preocupações centrais passou a ser a construção de uma quadra mais adequada, nomeando-se os:

\footnotetext{
(...) conhecidos mackenzistas Guilherme Gomes, Sylvio Fonseca e José Loureiro para a comissão pró-campo de basketball. Essa comissão já está em atividade, tanto assim que o local onde será construído o rinque já se acha nivelado. É do pensamento da referida comissão fazer inaugurar as novas instalações no próximo mês de novembro (JORNAL DOS SPORTS, 1933, p. 2).
}

A nova quadra foi inaugurada em dezembro de 1933. Logo em seguida, com grande festa, um celebrado torneio interno foi organizado (CORREIO DA MANHÃ, 1934). Na ocasião, "O basketplayer Armando Guimarães, autor da primeira cesta (...) recebeu um valioso cinto oferecido pela senhorita Onila do Amaral, 2 ${ }^{\text {a }}$ secretária do departamento feminino" (JORNAL DOS SPORTS, 1934, p. 2). Gradativamente, os atletas da bola ao cesto se tornariam 
ídolos do Mackenzie e do bairro do Méier.

A equipe da agremiação, a propósito, era formada por "elementos distintos (...) médicos, advogados, engenheiros e pessoas de destaque” (O JORNAL, 1934, p. 8). Tratava-se de forjar uma representação de clube de elite, algo que, de início, se manifestara no que tange ao envolvimento com o futebol (MELO; SILVA, 2021). Era clara a opção pelo amadorismo.

O debate acerca do profissionalismo pouco alcançava o basquete (GOMES, 2016). A diretoria do Mackenzie, em consonância, fazia questão de reforçar que o "(...) querido grêmio do Méier nunca mentiu ao seu passado - nasceu amadorista e continua praticando o amadorismo mais puro" (DIÁRIO DE NOTÍCIAS, 1939, p. 4). Enfatizava-se uma natureza associativa orientada "exclusivamente e continuamente" a alcançar os seus fins (WEBER, 1987, p. 105), como se não houvesse interesses outros, inclusive financeiros.

Em 1936, o $13^{\circ}$ Clube do bairro de Madureira desencadeou um movimento para que a Liga Carioca de Basquetebol organizasse uma seção somente destinada aos subúrbios. Certamente, tinha em conta o melhor desempenho das equipes da zona urbana, bem como a busca de maior possibilidade de intervenção na entidade representativa (JORNAL DOS SPORTS, 1933).

Em 1937, foi criada uma liga de basquetebol dos clubes dos subúrbios (O RADICAL, 1937). A essa altura, no futebol, o Mackenzie já estava filiado a uma entidade da zona suburbana (MELO; SILVA, 2021), mas não faria o mesmo com a modalidade da bola ao cesto.

Não surpreende que tenha figurado nas últimas colocações de um concurso promovido por um jornal local para eleger o clube mais querido dos subúrbios (O RADICAL, 1936). Como no caso do futebol, o Mackenzie mantinha-se dúbio no tocante ao trânsito entre os arrabaldes e o Centro/Zona Sul. Apresentava-se como representante da zona suburbana, mas dialogava mais intensamente com as realizações que tinham sede na zona urbana.

De fato, o Mackenzie aumentou sua inserção na Liga Carioca de Basquete, logrando conquistas que o alçaram à divisão principal, na qual pode disputar partidas com renomados clubes da cidade, como o Tijuca Tênis, Botafogo, Flamengo e Fluminense (JORNAL DO BRASIL, 1934). Uma vez mais conseguira tomar parte em esferas esportivas de maior prestígio.

Tendo em vista essa nova inserção, novos investimentos foram promovidos no sentido tanto de construir uma quadra mais adequada quanto de melhorar a performance de sua equipe, tendo convidado como "instrutor técnico" o “(...) devotado sportman Luiz Soares Filho", diretor de publicidade (JORNAL DOS SPORTS, 1934, p. 02) e "membro da comissão técnica" da Liga Carioca de Basquete (JORNAL DOS SPORTS, 1936, p. 2).

Mesmo com esses esforços, ao integrar uma divisão mais competitiva, os resultados deixaram de ser positivos, ocupando o clube, usualmente, as posições finais da classificação (JORNAL DOS SPORTS, 1935, p. 2), não poucas vezes sendo mesmo o "lanterna”. Era difícil o embate com as associações mais prestigiosas da cidade.

A Liga Carioca prosperava. Em seu balanço financeiro do ano de 1934, a entidade deu conta do sucesso de suas ações, declarando que arrecadara

[...] a respeitável cifra de Rs. 53:050\$600 [...], fato este que bastaria para atestar, de maneira eloquente, o crédito que, dia a dia, [...] dispensam todos os clubes que lhe pedem filiação [...] (JORNAL DOS SPORTS, 1935, p. 5). 
De outro lado, não era fácil para as agremiações menores arcarem com os custos necessários para manterem-se ativas nas iniciativas da entidade: manutenção da quadra, aquisição de equipamentos e uniforme, despesas de transporte, além das taxas cobradas pela Liga Carioca. Em 1935, por exemplo, a inscrição no campeonato anual foi estipulada em $50 \$ 000$ (A MANHÃ, 1935).

O Mackenzie sentia as dificuldades financeiras de permanecer na Liga Carioca, mas tal envolvimento se tornou uma prioridade. A ideia era transitar por um quadro privilegiado economicamente do esporte do Rio de Janeiro mesmo que os resultados nas quadras nem sempre fossem satisfatórios. A última posição no campeonato de 1935 é uma evidência disso (JORNAL DOS SPORTS, 1936).

Em 1936, tornou-se presidente do Mackenzie o antigo diretor de basquetebol: Newton Carvalho de Souza (GAZETA DE NOTÍCIAS, 1936). É possível que tal eleição seja um indicador do aumento da importância da modalidade no cotidiano do clube. Na mesma medida, pode ter se enfatizado ainda mais tal relevância, especialmente se considerarmos os esforços sistemáticos do corpo de associados para construção do "seu rink": "acabam de ofertar cimento os sportmen Paulo Santos, Antônio Soraes Levy Melo, Alfredo Silveira e Benjamin Blume" (JORNAL DOS SPORTS, 1936, p. 2).

De toda forma, mais do que nunca em sua trajetória, o basquete tornou-se o investimento central do Mackenzie. Colocou-se em pauta a criação de um departamento autônomo para a modalidade (JORNAL DOS SPORTS, 1938), bem como se tornou mais usual homenagear seus atletas de destaque (JORNAL DOS SPORTS, 1939, p. 3). O futebol fora substituído nas preferências da agremiação do Méier.

Mesmo com as limitações econômicas, na seara esportiva, o envolvimento com a modalidade da bola ao cesto tornou-se a principal referência pública do Mackenzie (GAZETA DE NOTÍCIAS, 1936). Isso ocorreu, inclusive, graças a sua presença constante em todas as ações da Liga Carioca de Basquetebol, notadamente nos torneios abertos, ocasiões que permitiam a participação ampliada dos interessados, não somente clubes filiados, mas também outras agremiações esportivas, bem como instituições escolares civis e militares (CORREIO DA MANHÃ, 1936). Em 1936, foram 47 equipes inscritas.

Destaca-se a relação estabelecida com as escolas, uma estratégia adotada pela Liga Carioca de Basquetebol para difundir a modalidade e se vincular aos temas educacionais importantes do momento. A entidade participou, inclusive, do V Congresso Brasileiro de Educação realizado no Rio de Janeiro, em 1935, ocasião na qual o esporte foi apresentado como um contributo para "(...) transformar a escola em uma referência cultural moderna, democrática, ativa e eficiente” (LINHALES, 2006, p. 95).

O discurso da diretoria do Mackenzie também estava alinhado à ideia de que a prática de esportes deveria ser balizada pela “(...) conhecida divisa 'mens sana e corpore sano” (JORNAL DOS SPORTS, 1934, p. 8), cuja finalidade seria o aprimoramento do “(...) espirito, instruindo e deleitando”. É importante pontuar que, desde os anos 1920, a cidade passava por novo ciclo de reformas urbanas nas quais essas dimensões, articuladas com as exigências do cenário 
nacional, se tornaram mais enfatizadas (SILVA, 2009) ${ }^{8}$.

A associação aqui estudada, em diversas ocasiões, estimulou o envolvimento de escolares ao promover torneios “(...) entre ginásios, colégios e institutos (...)" (JORNAL DOS SPORTS, 1939, p. 3). Além de ser um investimento em sua imagem pública, uma forma de explicitar seus compromissos sociais, a diretoria encarava essas iniciativas como uma maneira de descobrir talentos e reforçar suas equipes (JORNAL DOS SPORTS, 1940).

Em 1937, momento em que assistiu grande avanço com a instalação de sua sede social definitiva na Rua Dias da Cruz, onde se encontra até hoje, bem como com o arrendamento de um terreno na Rua Magalhães Couto para a construção de outra "praça de sports" (O RADICAL, 1938, p. 6), o Mackenzie conquistou o campeonato complementar da Liga Carioca de Basquete (GAZETA DE NOTÍCIAS, 1937).

Ainda que, no ano seguinte, esse bom resultado não se repetisse - ficou em último lugar em seu grupo no torneio principal (DIÁRIO DE NOTÍCIAS, 1938), o clube lograva conquistar uma repercussão que tanto esperava, afinal, segundo um cronista, tratava-se aquele campeonato do único na cidade com as "características de sensacionalismo" e "proporções inéditas, em virtude do número de participantes” (JORNAL DOS SPORTS, 1938, p. 3).

A situação junto à Liga Carioca de Basquetebol, contudo, permanecia problemática. Em 1939, por exemplo, quando logrou outro bom resultado, o $2^{\circ}$ lugar no campeonato complementar, ocasião comemorada efusivamente na sede da Dias da Cruz (JORNAL DO COMMERCIO,1939), bem como inaugurou outra quadra para a prática da modalidade (JORNAL DOS SPORTS, 1939), seguia existindo uma pendência financeira com a entidade representativa (A NOITE, 1939).

Já sob a presidência de Carlos Lopes Guimarães (1939), comerciante do bairro e devotado sportman, uma nova mensalidade foi criada para a categoria de sócios aspirantes ${ }^{9}$, no valor de $5 \$ 000$, destinada a contratar um "preparador para os que desejavam praticar o basquetebol" (O RADICAL, 1939, p. 7). Em 1940, foi criada a equipe feminina (JORNAL DOS SPORTS, 1940) consagrando um protagonismo das mulheres que sempre fora usual na história do clube (MELO; SILVA, 2021). Àquela altura, o Mackenzie era considerado "modelar”, um diferencial no subúrbio, contando com "(...) numerosos departamentos esportivos, um bem organizado gabinete médico e seu seleto quadro social (...)” (O IMPARCIAL, 1941, p. 15).

Em 1941, já consolidada a estratégia que confirmava certo reconhecimento no Rio de Janeiro, nas zonas urbana e suburbana, com uma missa realizada na Igreja da Candelária, bem como muitas cerimônias e atividades festivas, o Mackenzie comemorou seus 27 anos vislumbrando um futuro promissor (DIÁRIO CARIOCA, 1941). Durante décadas, no âmbito esportivo, seria reconhecido por seu envolvimento com o basquete.

\section{CONSIDERAÇõES FINAIS}

Este artigo tratou da experiência de envolvimento com o basquete entabulada no Sport Club Mackenzie, uma importante associação do distrito/bairro do Méier, localizado numa

8 Em diversos períodos, o esporte tornou-se, de alguma forma e em diferentes graus, motivo de atenção dos poderes públicos, tendo em conta encaminhar alguns de seus intuitos para o país. Ver, por exemplo, Drumond (2008) e Couto (2014).

9 Naquele tempo, havia três categorias de jogadores: oficiais, aspirantes e principiantes (JORNAL DOS SPORTS, 1939). 
região fronteiriça entre as zonas urbana e suburbana do Rio de Janeiro. Formado por uma elite local, a agremiação buscou constantemente assumir uma função de liderança e contribuição com o desenvolvimento local.

Com o intuito de buscar maior representatividade no cenário esportivo do Rio de Janeiro, o Mackenzie sempre procurou se filiar às ligas mais prestigiosas da cidade, procedimento que se iniciou no âmbito do futebol com sua adesão à Liga Metropolitana de Esportes Atléticos e à AMEA. No que tange à prática do velho esporte bretão, todavia, o clube encontrou muitas dificuldades administrativas, o que resultou em um posterior relacionamento com entidades suburbanas.

Sua filiação à Liga Carioca de Basquetebol foi interpretada como uma possibilidade de voltar a ter representatividade no cenário citadino. Mesmo também enfrentando dificuldades de natureza administrativa e econômica, não se mostrou disposto ao envolvimento com as iniciativas eminentemente suburbanas, uma expressão da sua identidade ambígua, típica do bairro no qual se localizava e tanto buscava representar.

No caso do basquetebol, conseguiu maior sucesso do que no futebol, inclusive porque o primeiro não era tão custoso quanto o segundo. O envolvimento com a modalidade da bola ao cesto permitiu novas vinculações e projeções públicas que fortaleceram a imagem do clube, indo ao encontro de seus intuitos de transitar entre as elites da cidade do Rio de Janeiro.

Mais do que uma reflexão sobre a ampliação da cultura esportiva do Rio de Janeiro, em especial no que diz respeito ao basquete, esta pesquisa nos permite lançar um olhar para os relacionamentos entre as elites das zonas urbanas e suburbanas, explicitando posicionamentos assumidos por certos grupos sociais para buscar inserção em um cenário citadino progressivamente complexo e em constante transformação. 


\section{REFERÊNCIAS BIBLIOGRÁFICAS}

ABREU, Maurício. A evolução urbana do Rio de Janeiro. Rio de Janeiro: IPLANRIO, 1987.

BRASIL. Diretoria Geral de Polícia Administrativa, Arquivo e Estatística. Recenseamento do Rio de Janeiro (Distrito Federal): realizado em 20 de setembro de 1906. Rio de Janeiro: Oficina de Estatística, 1907.

BRASIL. Recenseamento do Brasil realizado em 1 de setembro de 1920: população do Rio de Janeiro (Distrito Federal). V. II, 1a Parte. Rio de Janeiro: Tipografia da Estatística, 1923.

CANCELA, Karina. A fundação da primeira sede da Associação Cristã de Moços na América Latina e sua atuação como fomentadora da prática esportiva no Rio de Janeiro pós-

republicano. Recorde: Revista de História do Esporte, v. 3, n. 2, dez. 2010. Disponível em: https:// revistas.ufrj.br/index.php/Recorde/article/view/737/680. Acesso em 5 jun. 2020.

CHARTIER, Roger. O mundo como representação. Estudos Avançados, São Paulo, v.

5, n. 11, p. 173-191, abr. 1991. Disponível em: https://www.scielo.br/scielo.php?script=sci arttext\&pid=S0103-40141991000100010 Acesso em 16 nov. 2020.

COUTO, Euclides de Freitas. Da ditadura à ditadura: uma história política do futebol brasileiro (1930 - 1978). Niterói: Editora da UFF, 2014.

DRUMOND, Maurício. Nações em jogo: esporte e propaganda política em Vargas e Perón. Rio de Janeiro: Apicuri, 2008.

FERNANDES, Nelson da Nobrega. O conceito carioca de subúrbio. Um rapto ideológico. Revista FAU/UFR J, Rio de Janeiro, n. 2, p. 8-15, 2009.

FERREIRA JUNIOR, Rolando. NBA, CBB E NLB: relações de poder no universo organizacional do basquetebol brasileiro. Dissertação (Mestrado em Educação Física). Curitiba: UFPR, 2008.

GOMES, Eduardo de Souza. O futebol vira profissão: tensões e efeitos da profissionalização do futebol no Rio de Janeiro (1933-1941) e na Colômbia (1948-1954). Dissertação (Mestrado em História Comparada). Rio de Janeiro: UFRJ, 2016.

LEFEBVRE, Henri. Espaço e política. Belo Horizonte: Editora UFMG, 2008.

LINHALES, Meily A. A produção de uma forma escolar para o esporte: os projetos culturais da Associação Brasileira de Educação (1926-1935) como indícios para a Historiografia da Educação Física. In: TABORDA DE OLIVEIRA, Marcus Aurélio (org.). Educação do corpo na escola brasileira. Campinas: Autores Associados, 2006. p. 93-110.

MELO, Victor Andrade de; SILVA, Bruno Adriano Rodrigues da. Estratégias do subúrbio: a experiência do Sport Club Mackenzie (Rio de Janeiro; 1914-1932). Projeto História, São Paulo, no prelo, 2021.

MENDONÇA, Leandro Clímaco. Nas margens: experiências de suburbanos com periodismo no Rio de Janeiro, 1880-1920. Dissertação (Mestrado em História). Niterói: UFF, 2011.

MIYASAKA, Cristiane Regina. Os trabalhadores e a cidade: a experiência dos suburbanos cariocas (1890-1920). Tese (Doutorado em História). Campinas: Unicamp, 2016.

PARETO, Vilfredo. Circulação das Elites. In: CRUZ, M. B (org.). Teorias sociológicas: os fundadores e os clássicos (antologias de textos). Lisboa: Fundação Calouste Gulbenkian, 2010. 
PEREIRA, Leonardo Affonso de Miranda. Footballmania: uma história social do futebol no Rio de Janeiro, 1902-1938. Rio de Janeiro: Nova Fronteira, 2000.

SANTOS, João Manuel Casquinha Malaia. O processo de profissionalização do futebol no Rio de Janeiro: dos subúrbios à Zona Sul. A inserção de negros, mestiços e brancos pobres na economia da Capital Federal (1914-1923). Leituras de Economia Política, Campinas, n. 13, p. 125155, jan./jul. 2008. Disponível em: https://www.eco.unicamp.br/images/arquivos/artigos/LEP/ L13/MALAIA_6_13.pdf Acesso em 29 out. 2020.

SANTOS, João Manuel Casquinha Malaia. Revolução vascaína: a profissionalização do futebol e inserção socioeconômica de negros e portugueses na cidade do Rio de Janeiro (1915-1934). Tese (Doutorado em História). São Paulo: USP, 2010.

SILVA, José Cláudio Sooma. Teatros da modernidade: representações de cidade e escola primária no Rio de Janeiro e em Buenos Aires nos anos 1920. Tese (Doutorado em Educação). Rio de Janeiro: UERJ, 2009.

SILVA, Mayara Grazielle Consentino Ferreira da. Algumas considerações sobre a reforma urbana Pereira Passos. Urbe: Revista Brasileira de Gestão Urbana, Curitiba, v.11, e 10180179, 2019. Disponível em: https://www.scielo.br/scielo.php?script=sci_abstract\&pid=S2175$\underline{3692019000100263 \& \operatorname{lng}=\mathrm{pt \& nrm}=\text { iso. }}$. Acesso em 18 set. 2020.

SOARES, Antônio Jorge. O racismo no futebol do Rio de Janeiro nos anos 1920: uma história de identidade. Revista Paulista de Educação Fisica, São Paulo, v. 13, n. 1, p. 119-29, jan.-jun. 1999. Disponível em: http://www.revistas.usp.br/rpef/article/view/137764. Acesso em 18 set. 2020.

\section{FONTES}

A CLASSIFICAÇÃO Final depois do returno do Campeonato de Basketball. Diário de Notícias, 21 dez. 1938, p. 15.

AFINAL, vence a Força de Vontade. O Radical, 20 jul. 1938, p. 6.

A FORMAÇÃO da Liga Carioca de Baketball. Jornal dos Sports, 15 fev. 1933, p. 1.

A GRANDE festa sportiva de domingo no campo do S. Christovam. Jornal do Brasil. 10 jan. 1915a, p. 15.

A LIGA Suburbana de Basketball já é uma realidade. O Radical, 4 nov. 1937, p. 7.

A PALPITANTE Questão do Momento. O Imparcial. 14 de marc. 1924, p. 11.

APEZAR dos pesares. Jornal dos Sports, 2 fev. 1935, p. 5.

A SESSÃO cinematographica do Tricolor. Jornal do Brasil, 21 out. 1920, p. 11.

AS RESOLUÇÕES da Assemblea da Liga. Jornal do Brasil, 24 set. 1919, p. 11.

ASSOCIAÇÃO Metropolitana de Esportes Athleticos. Jornal do Brasil, 23 mai. 1925, p. 20.

ASSOCIAÇÃO Metropolitana de Esportes Athléticos. O Imparcial. 01 de março de 1926, p. 11.

A ULTIMA Rodada do Campeonato da 2 divisão da AMEA. Jornal dos Sports, 4 dez. 1931, p. 1.

BASKETBALL. Correio da Manhã, 4 fev. 1934, p. 10.

BASKETBALL. Correio da Manhã, 12 mai. 1929, p. 11.

BASKETBALL. Correio da Manhã. 12 jun. 1930, p. 08. 
BASKETBALL. Diário Carioca, 2 dez. 1932, p. 7.

BASKET-BALL. Gazeta de Notícias, 28 dez. 1915, p. 5.

BASKET-BALL. Jornal do Brasil, 30 mar. 1914, p. 1.

BASKET-BALL. Jornal do Brasil, 10 out. 1924, p. 21.

BASKET-BALL. Jornal do Commercio, 25 jul. 1918, p. 6.

BASKETBALL. Jornal do Commercio, 27 jul. 1928, p. 7.

BASKET-BALL. Jornal do Commercio, 28 set. 1919, p. 5.

BASKETBALL. Jornal dos Sports, 11 ago. 1933, p. 10.

BASKETBALL. Jornal dos Sports, 13 jan. 1934, p. 2.

BASKET-BALL. O Imparcial, 25 set. 1919, p. 19.BASKET. Correio da Manhã, 16 mai. 1936, p. 12.

BASKET. Jornal do Commercio, 21 ago. 1921, p. 6.

BOA DEMONSTRAÇÃO. Jornal dos Sports, 4 de set. 1934, p. 02.

CAMPEONATO de basketball do Rio de Janeiro. Jornal do Brasil, 28 jan. 1915b, p. 12.

COM O SPORT Club Mackenzie. A Nação. 21 de mai. 1933, p. 23.

CRITICAS e Sugestões: o progresso do Basketball. Jornal do Sports, 13 jun. 1931, p. 2.

DIÁRIO Oficial da União, 31 mar. 1925, p. 70.

DIÁRIO Oficial da União, 9 out. 1935, p. 52.

ESTATUTOS da AMEA. O Imparcial. 29 de mar. 1924, p. 10.

FESTAS. Gazeta de notícias, 28 nov. 1911, p. 5.

FOI empossada a nova diretoria do Sport Club Mackenzie. Gazeta de Notícias, 14 fev. 1936, p. 11.

FOOTBALL. A Noite, 24 fev. 1932, p. 11.

FOOTBALL. Correio da Manhã, 3 fev. 1931, p. 10.

FOOTBALL. O Imparcial, 15 mar. 1924, p. 11.

FUNDADA desde hóntem a Liga Carioca de Basketball. Jornal dos Sports, 11 mai. 1933, p. 3.

FUTEBOL. Jornal do Comércio. 12 dez. 1916, p. 6.

GAZETA de Notícias, 28 abr. 1885, p. 3.

GAZETA de Notícias, 21 nov. 1884, p. 4.

INAUGURAÇÃO da nova quadra do S. C. Mackenzie. Jornal dos Sports, 10 jan. 1939, p. 3.

JARDIM Zoológico. O Paiz, 5 jun. 1914, p. 16.

LAWN-TENNIS. O Imparcial. 10 jun. 1916, p. 9.

LIGA Carioca de Basketball. A Manhã, 15 mai. 1935, p. 0.

LIGA Carioca de Basketball. Jornal do Brasil, 10 de ago. 1934, p. 24.

LIGA Metropolitana de Sports Athleticos. Jornal do Brasil, 15 set. 1926, p. 10. 
MACKENZISTAS. Jornal do Sports, 12 mar. 1938, p. 3.

MELHORAMENTOS suburbanos. Revista Suburbana, 6 jul. 1918, p. 18.

MOVIMENTO Desportivo dos Clubs Suburbanos. O Jornal, 15 dez. 1929, p. 10.

NA FEDERAÇÃO A. Suburbana. 16 abr. 1939, p. 15.

NA LIGA Carioca de Basketball. Gazeta de Notícias, 12 nov. 1937, p. 9.

NO MACKENZIE. Jornal dos Sports. 22 de mar. 1939, p. 04.

NO MACKENZIE. Jornal dos Sports, 9 out. 1940, p. 3.

NO SPORT Club Mackenzie. Jornal dos Sports, 9 ago. 1939, p. 3.

NOTAS oficiaes da AMEA. Jornal do Brasil, 20 mai. 1925, p. 19.

NOVO uniforme do S. C. Mackenzie. A Nação, 14 mai. 1933, p. 22.

NUMEROSAS Designações no Ministério da Fazenda. Correio da Manhã. 09 de jul. 1930, p. 08.

O ANIVERSÁRIO do vitorioso Sport Club Mackenzie. Diário de Notícias, 15 mar. 1931, p. 10.

O ANIVERSÁRIO do Sport Club Mackenzie. Jornal dos Sports, 16 mar. 1939, p. 4.

O CERTAME da L.C.B. será disputado em três grupos. Jornal dos Sports, 29 abr. 1938, p. 3.

O GRANDE macht Internacional hoje. Jornal do Brasil, 6 jan. 1929, p. 14.

O INÍCIO Sensacional das atividades da Federação Atletica Suburbana. A Noite. 22 de abril 1939, p. 7.

O MACKENZIE ao seu cestinha. Jornal dos Sports, 4 jan. 1939, p. 3.

O MACKENZIE festeja o 27o aniversário de sua fundação. Diário Carioca, 14 mar. 1941, p. 9.

O RINK do S. Club Mackenzie. Jornal dos Sports, 10 out. 1933, p. 2.

OS ASSOCIADOS do Centro União dos Empregados da Central do Brasil (...). Correio da Manhã. 27 de fev. 1921, p. 04.

O S. C. MACKENZIE, em seus vinte annos de existência obras meritoriais. O Jornal, 31 mar. 1934, p. 8.

O S. C. MACKENZIE reintegrado em seus direitos na L. C. B. Jornal do Sports, 22 abr. 1938, p. 3.

O SPORT Club Mackenzie chama seus amadores de Basketball. Diário da Noite. 18 de julho de 1930, p. 06.

O TORNEIO de perdedores e o Campeonato da 2 divisão. Jornal dos Sports, 30 jan. 1935, p. 2.

POR 5:000\$000! O Radical, 30 dez. 1936, p. 7.

PORQUE o Mackenzie abandonou o torneio da segunda divisão. Correio da Manhã, 14 ago. 1932, p. 19.

PRO-RINK. Jornal dos Sports, 18 jan. 1936, p. 2.

QUADRO Demonstrativo dos resultados do campeonato carioca de basket de 1935. Jornal dos Sports, 1 mar. 1936, p. 2.

RIACHUELO Foot-ball Club. Jornal do Brasil. 21 de out. 1905, p. 5.

SPORT Club Mackenzie. Gazeta de Notícias, 11 jul. 1925, p. 6. 
SPORT Club Mackenzie tem nova directoria. O Jornal, 16 jan. 1931, p. 13.

TODOS os Sports. Jornal do Commercio, 11 nov. 1939, p. 10.

TORNEIO De Basket do Sport Club Mackenzie. Jornal dos Sports. 18 de set. 1940, p. 03.

TORNEIO Initium de Basketball. Jornal do Brasil, 22 mai. 1923, p. 15.

ULTIMAS Suburbanas. O Imparcial, 13 mar. 1941, p. 15.

UMA NOVA Mensalidade no Mackenzie. O Radical, 30 dez. 1939, p. 7.

VIDA suburbana. Méier. Revista da Semana, 31 jan. 1909, p. 9.

VISANDO o progresso do basket nos subúrbios. Jornal dos Sports, 3 dez. 1933, p. 2. 